\title{
Hearing disability in patients with Fuchs' endothelial corneal dystrophy: unrecognized co-pathology?
}

This article was published in the following Dove Press journal:

Clinical Ophthalmology

8 September 201I

Number of times this article has been viewed

\section{Marilette Stehouwer \\ Ward R Bijlsma \\ Allegonda Van der Lelij \\ Department of Ophthalmology, University Medical Center Utrecht, Utrecht, The Netherlands}

Purpose: To investigate a possible association between Fuchs' endothelial corneal dystrophy (FECD) and hearing disability.

Methods: A cross-sectional observational study was performed at the University Medical Center Utrecht. Cases and controls were patients who were treated by a cornea specialist between 2004 and 2008. FECD patients had either already undergone or were planned for a keratoplasty procedure. All controls were patients treated for cataract without any corneal pathology. Cases and controls were matched by age group and gender. A structured telephone interview combined with a validated self-perceived hearing function test (the Hearing Handicap Inventory for the Elderly, screening version; HHIE-S) was used for data collection.

Results: Hearing disability was reported in 33 patients $(45.8 \%)$ in the FECD-group ( $\mathrm{n}=72$, average age: 73 years) versus 50 patients $(34.7 \%)$ in the control group $(n=144$, average age: 73 years). Hearing disability was significantly associated with FECD after adjustment for age, noise exposure, and diabetes mellitus (odds ratio 1.97 95\% confidence interval 1.04-3.75).

Conclusion: This case-control study reports a significant association between FECD and hearing disability. The causal relation was not evaluated in this study, though mutations in the SLC4A11 gene could have played an important role. This gene encodes for an ion transporter, which has been found in the cornea and inner ear. With the lack of examination with a pure tone or speech audiometry in this study, further studies need to be performed in order to support the association and should include a complete ENT examination with audiometry and genetic research.

Keywords: hearing disability, hearing impairment, Fuchs' endothelial corneal dystrophy

\section{Introduction}

Fuchs' endothelial corneal dystrophy (FECD) is a progressive degeneration of the corneal endothelium that can lead to corneal opacification, resulting in the need for a keratoplasty procedure in the final stage. FECD is the most common posterior corneal dystrophy affecting elderly patients, with a preference for women. ${ }^{1-3}$ The exact incidence of FECD is not known. The most common first sign of the disease is the formation of guttate excrescences. The cornea guttata are seen quite often and increase with age. No consistent figures are available. In a recent population-based study in Japan, for example, the prevalence of cornea guttata was $4.1 \%$ among residents of $\geq 40$ years $^{4}$, whereas in the Reykjavik Eye Study a prevalence of $9.2 \%$ was found in participants of $\geq 55$ years. ${ }^{5}$

The posterior corneal dystrophies are all thought to represent defects of neural crest terminal differentiation. ${ }^{1-3,6}$ In FECD, this results in a dysfunction of the endothelium, 
a monolayer of cells which normally maintains corneal clarity by keeping the stroma in a state of relative dehydration and providing coverage of the posterior corneal surface. ${ }^{2,7}$ Although FECD is a common disorder, described by Ernst Fuchs in $1910,{ }^{6}$ the knowledge of etiology and disease progression in this age-related endothelial dystrophy is still limited. The disorder is usually sporadic, but familial highly penetrant forms with an autosomal dominant inheritance pattern have been described. ${ }^{3,8-10}$

At our institution (University Medical Center Utrecht, UMCU), a high frequency of hearing impairment among FECD patients was subjectively observed. Due to the limited knowledge of the etiology of FECD, co-pathology in other organs could have remained unrecognized.

The combination of an endothelial dystrophy and sensorineural hearing loss is not a rare phenomenon. Among the posterior corneal dystrophies, Harboyan syndrome is known as a corneal dystrophy and perceptive deafness (CDPD), usually developing during the second decade of life. ${ }^{11,12}$ A recent study showed that mutations in the SLC4A11 gene will result in endothelial dystrophy and sensorineural hearing loss. This mutation has been found in Harboyan syndrome as well as FECD and raised the question whether the subjectively observed high frequency of hearing disability among FECD patients is not merely a coincidence.

This case-control study was performed to examine the hypothesis of whether FECD and hearing disability are associated.

\section{Materials and methods}

\section{Study design and study population}

A case-control study, cross-sectional observational, was conducted at UMCU, The Netherlands, following the tenets of the Helsinki declaration of 1975 and approved by the accredited Medical Review Ethics Committee of the UMCU. Initially, all patients who were examined by the cornea specialist and diagnosed with FECD between 2004 and 2008, were included in the study if they had either already undergone or were planned for a keratoplasty procedure. For each case, 2 controls were randomly selected from cataract surgery patients, operated in the same time period and with frequency-matching on 5-year age group and gender. Patients with cognitive disorders or who did not consent to participation were excluded, as were controls with corneal pathology.

\section{Data collection}

All eligible participants (both FECD and controls) received a letter, consisting of an information form and the questionnaire which was used in this study. One week later, participants were contacted by telephone and were interviewed. This time interval was chosen to provide participants sufficient time to study the questionnaire, and to minimize the chance that questions were unclear during the telephone interview. All interviews were performed by one of the authors (MS) who was not blinded for case-control status. Five attempts without establishing telephone contact resulted in an exclusion from the study. Relevant information on ocular pathology was obtained from the patient record.

\section{Study instrument}

The questionnaire was conducted as a telephone interview, enabling a large cohort group of patients and controls to be reached. The main topic of the questionnaire was the validated self-perceived hearing function test: the Hearing Handicap Inventory for the Elderly screening version (HHIE-S). An additional topic in the questionnaire were the factors that could have had an influence on the patient's hearing function (possible risk factors): noise exposure (during leisure and work), ear- and hearing-related medical history (wearing a hearing aid, prior ear surgery and/or pathology), diabetes mellitus, ${ }^{13}$ myotonic dystrophy, ototoxic medication, smoking (positive if previously or presently smoking), and level of education (primary, secondary, and higher education).

The HHIE-S version ${ }^{14,15}$ is a validated 10 -item questionnaire and scores each answer. The total scores range from 0 (no handicap) to 40 (maximum handicap). Different studies provided by ear/nose/throat (ENT) physicians found that this test is able to accurately diagnose hearing disability with a scores of $\geq 10$ (sensitivity $0.58-0.74$, specificity $0.68-0.85$ ) compared with pure tone audiometry. ${ }^{15-19}$ An HHIE-S score of $\geq 10$ was considered a hearing disability in this study.

\section{Statistical analysis}

Statistical analysis was performed by SPSS, version 15.0 for Windows. The discrete variables were measured with Chi-square test and Fischer's exact test. The independentsamples $t$-test was used for continuous nominal distributed variables.

Using binary logistic regression, the association between FECD and hearing disability was corrected for confounders that changed the odds ratio (OR) by $>5 \%$. A $P$ value of $<0.05$ was considered statistically significant.

\section{Results}

Based on patients' records, in total 87 patients with FECD were eligible to be enrolled in our study. Five patients had 
passed away and 72 of the 82 invited patients agreed to participate. Of the non-participants, 3 were unreachable by telephone and 7 patients were unwilling to participate. For the included 72 FECD patients, 180 matched controls were found based on patient records. Of the 180 invited controls 144 agreed to participate. Of the non-participants, 20 were unreachable by telephone and 16 patients were unwilling to participate. The main reason for declining participation for both groups was overall severe illness and living abroad. All participants (FECD and controls) completed their interview and there were no difficulties in obtaining the answers.

Overall, 216 participants (72 FECD patients and 144 controls) were enrolled in this case-control study, patient age ranging between 53 and 91 years (mean 73.4 years \pm 8.9 ) and a male:female ratio of 1:1. Table 1 shows the baseline characteristics, with no significant differences between the FECD and the control group. Possible risk factors for hearing disability are shown in Table 2, with age as a significant risk factor and noise exposure almost reaching significance. None of the participants were diagnosed with myotonic dystrophy. Chi-square and $t$-tests were used for $P$-value calculations in Tables 1 and 2. Overall, 83 participants reported hearing disability in accordance with the HHIE-S. A higher percentage in the FECD group reported hearing disability (45.8\%, 33 patients) compared with the control group (34.7\%, 50 controls) (OR 1.59; 95\% confidence interval [CI] $0.89-2.83$ ) (Table 3). This is in accordance with the $P$ value of 0.14 , reflecting the crude association between FECD and hearing disability (Table 2 ). Therefore we performed binary logistic regression to show an association between FECD and hearing disability after correction for confounders. Age, noise exposure, and diabetes mellitus changed the OR by more

Table I Baseline characteristics of the study population

\begin{tabular}{|c|c|c|c|c|c|}
\hline \multirow{2}{*}{$\begin{array}{l}\text { Characteristic } \\
\text { All subjects }\end{array}$} & \multicolumn{2}{|c|}{$\begin{array}{l}\text { FECD } \\
\text { no. (\%) }\end{array}$} & \multicolumn{2}{|c|}{$\begin{array}{l}\text { Controls } \\
\text { no. (\%) }\end{array}$} & $P$ value \\
\hline & 72 & & 144 & & \\
\hline Age $^{\mathrm{a}}$ Mean, SD & 73.4 & \pm 9.2 & 73.4 & \pm 8.9 & 0.97 \\
\hline Gender ${ }^{\mathrm{a}}$ Male & 35 & $(48.6)$ & 70 & $(48.6)$ & 1.0 \\
\hline Noise exposure & 7 & $(9.7)$ & 22 & $(15.3)$ & 0.30 \\
\hline Ototoxic medication & 0 & $(0)$ & 1 & $(0.7)$ & 1.0 \\
\hline Ear history ${ }^{b}$ & 6 & (8.3) & 16 & (II.I) & 0.64 \\
\hline Diabetes mellitus & 5 & (6.9) & 20 & (13.9) & 0.18 \\
\hline Smoking & 41 & $(56.9)$ & 82 & (56.9) & 1.0 \\
\hline \multicolumn{6}{|l|}{ Level of education } \\
\hline Primary & 20 & $(27.8)$ & 33 & $(23.2)$ & \\
\hline Middle & 24 & $(33.3)$ & 51 & $(35.9)$ & 0.80 \\
\hline High & 28 & (38.9) & 58 & $(40.8)$ & \\
\hline
\end{tabular}

Notes: aMatching variables; 'ear and hearing-related medical history.

Abbreviations: FECD, Fuchs' endothelial corneal dystrophy; HD, hearing disability; $\mathrm{SD}$, standard deviation.
Table 2 Overview of the risk factors

\begin{tabular}{|c|c|c|c|c|c|}
\hline \multirow{2}{*}{$\begin{array}{l}\text { Risk factor } \\
\text { All subjects } N=216\end{array}$} & \multicolumn{2}{|c|}{$\begin{array}{l}\text { With HD } \\
\text { no. (\%) }\end{array}$} & \multicolumn{2}{|c|}{$\begin{array}{l}\text { Without HD } \\
\text { no. (\%) }\end{array}$} & \multirow[t]{2}{*}{$P$ value } \\
\hline & 83 & $(38.4)$ & 133 & $(61.6)$ & \\
\hline FECD & 33 & (39.8) & 39 & $(29.3)$ & 0.14 \\
\hline Age Mean, SD & 77.1 & \pm 7.8 & 71.1 & \pm 8.9 & 0.00 \\
\hline Gender Male & 40 & $(48.2)$ & 65 & $(48.9)$ & 1.0 \\
\hline Noise exposure & 16 & $(19.3)$ & 13 & $(9.8)$ & 0.06 \\
\hline Ototoxic medication & 1 & $(1.2)$ & 0 & $(0)$ & 0.38 \\
\hline Ear history ${ }^{\mathrm{a}}$ & 12 & $(14.5)$ & 10 & $(7.5)$ & 0.11 \\
\hline Diabetes mellitus & 12 & $(14.5)$ & 13 & $(9.8)$ & 0.38 \\
\hline Smoking & 51 & $(61.4)$ & 72 & (54.I) & 0.32 \\
\hline \multicolumn{6}{|l|}{ Level of education } \\
\hline Primary & 26 & $(31.7)$ & 27 & $(20.5)$ & \\
\hline Middle & 27 & (32.9) & 48 & $(36.4)$ & 0.17 \\
\hline High & 29 & $(35.4)$ & 57 & $(43.2)$ & \\
\hline
\end{tabular}

Note: aEar and hearing-related medical history.

Abbreviations: FECD, Fuchs' endothelial corneal dystrophy; HD, hearing disability; $\mathrm{SD}$, standard deviation.

than $5 \%$ and were included in the binary logistic regression to describe the unbiased association between FECD and hearing disability. After adjustment for age, noise exposure, and diabetes mellitus, a significant association was found between FECD and hearing disability (OR 1.97; 95\% CI 1.04-3.75).

\section{Discussion}

This case-control study reported a significant association between FECD and hearing disability with an OR of 1.97 (95\% CI 1.04-3.75) after correction for confounders. In the FECD group, $45.8 \%$ reported a hearing disability in accordance with the HHIE-S; this was $34.7 \%$ in the control group.

The first signs of FECD become evident in the fourth or fifth decade of life, but often do not produce symptoms until a decade or more later. The mean age of the participants (73.4 years) in this study is comparable with that of the general patient population with FECD who are under (short- or long-term) treatment of a cornea specialist. Patients and medical professionals often consider hearing loss as an age-related, physiological change. Hence, an association between FECD and hearing disability in this elderly patient group may have been overlooked in clinical practice by ophthalmologists.

Congenital corneal endothelial dystrophy (CHED2) and Harboyan syndrome (CDPD), both syndromes with sensorineural hearing loss, are associated with mutations in the SLC4A11 gene, whereas heterozygous mutations in the SLC4A11 gene are found in the late-onset FECD..$^{10,12,20-22}$ The SLC4A11 gene encodes for an ion-transporter and is essential for cell growth, proliferation and differentiation, as early as during the embryonic stage. The ion transporter SLC4A11 
Table 3 Crude and adjusted associations between hearing impairment and FECD

\begin{tabular}{|c|c|c|c|c|c|}
\hline \multirow[t]{2}{*}{ Variable } & \multicolumn{2}{|c|}{ No. of subjects (\%) } & \multirow[t]{2}{*}{ Total no. } & \multirow{2}{*}{$\begin{array}{l}\text { Unadjusted odds ratio } \\
(95 \% \mathrm{CI})\end{array}$} & \multirow{2}{*}{$\begin{array}{l}\text { Adjusted odds ratio } \\
(95 \% \mathrm{CI})\end{array}$} \\
\hline & FECD & Controls & & & \\
\hline HD yes & $33(45.8)$ & $50(34.7)$ & 83 & I.59 (0.89-2.83) & 1.97 (1.04-3.75) \\
\hline HD no & $39(54.2)$ & $94(65.3)$ & 133 & & \\
\hline
\end{tabular}

Notes: adjusted for age, noise exposure, and diabetes mellitus.

Abbreviations: FECD, Fuchs' endothelial corneal dystrophy; $\mathrm{HD}$, hearing disability; $\mathrm{Cl}$, confidence interval.

can mediate the flux of $\mathrm{Na}^{+}$and $\mathrm{OH}^{-}$into cells and $\mathrm{Na}^{+} /$borate co-transport in the presence of borate. ${ }^{21-23}$

The association between endothelial dystrophy and hearing impairment has recently been shown in an experimental model, where mutations in the SLC4A11 gene resulted in deafness, endothelial dystrophy, and polyuria. ${ }^{20}$ In this mouse model SLC4A11 is expressed in the endothelium of the cornea, in the thin descending part of Henle's loop in the kidney, and in fibrocytes of the inner ear. The role of SLC4A11 in the mice was studied by inactivation of the gene by targeted mutagenesis, which resulted in corneal dystrophy, deafness, and polyuria. ${ }^{20}$ The cornea of the knock-out mice showed a thickening of several layers, an increased sodium concentration in endothelial cells, and an accumulation of sodium chloride in the corneal stroma. Because the SLC4A11 can act as a sodium channel, this suggests that the loss of SLC4A11 results in a disturbance of ion gradients and will disrupt the intricate balance of the flux of fluids. The inner ear showed severe disruptions in the typical morphology of fibrocytes with numerous intracellular vacuolations and extracellular edemas, also indicating a disturbance of the osmotic balance of these cells. A strongly reduced endocochlear potential was measured in the SLC4A11 knock-out mice. The reduction of the endocochlear potential disables outer hair cells to amplify auditory signal.

The findings of Gröger et al combined with reports of heterozygous mutations of SLC4A11 in the late-onset FECD, could support the association between hearing disability and FECD found in this study. With the use of a validated test, this study measured the frequency of hearing disability among participants and did not investigate the cause (inner-, middle- or external-ear) and type (conductive or perceptive) of hearing impairment, while the hypothesis of the association is based on perceptive hearing loss, ie, sensorineural hearing loss as a result of a malfunction of the sensory cells and the nerve fibers in the inner ear. Further research should be performed with at least routine ENT examination and pure tone as well as speech audiometry. To support the above-mentioned hypothesis, genetic testing in these individuals could shed light on the association between FECD and hearing disability.
Potential limitations of our analysis include the selfperceived hearing function used, although this is a validated test. There was no additional audiometric proof of the hearing disability in the participants who reported this according to the questionnaire. However, the HHIE-S is a widely used, well-validated questionnaire and a threshold of $\geq 10$, as used in this study, maximizes the test accuracy. With this cut-off score, the sensitivity ranges from 0.58 to 0.74 , and specificity from 0.68 to $0.85 .{ }^{14-19,24}$ The recall-based assessments of all hearing disability-related information could also lead to measurement errors, although these had equal chances of occurring in both groups. In an attempt to minimize inter-observer bias, all interviews were performed by only one interviewer. In addition, the interviews were performed unblinded, which could have influenced our results. Hearing impairment was reported more frequently in the FECD group than in the control group, but did not reach significance without correcting for confounders. A possible explanation is the relatively small study population, which can be confirmed by the low significance rate of risk factors in Table 2 and the almost equal gender ratio. In addition, this study did not perform genetic testing. In accordance with the literature, ${ }^{12}$ only some of our FECD participants could have had the mutation in the SLC4A11 gene. Based on the above-mentioned hypothesis, only the participants with this mutation could have been responsible for the association with hearing disability; this remains to be investigated.

In conclusion, this study reported a strong association between FECD and hearing disability. It suggests that hearing disability could be a co-pathology in FECD, though this study did not investigate the causal relationship between FECD and hearing disability. Further studies including ENT examination with pure tone as well as speech audiometry in combination with genetic research to evaluate the presence of the SCLAA11 mutation, need to be performed to support our hypothesis of an association between (a subgroup of) FECD and hearing disability.

\section{Acknowledgment}

The authors thank J Buwalda, ENT specialist for critically reading the manuscript. 


\section{Disclosure}

The authors disclose no conflicts of interest or receipt of funding for this study.

\section{References}

1. Bahn CF, Falls HF, Varley GA, Meyer RF, Edelhauser HF, Bourne WM. Classification of corneal endothelial disorders based on neural crest origin. Ophthalmology. 1984;91:558-563.

2. Bergmanson JP, Sheldon TM, Goosey JD. Fuchs' endothelial dystrophy: a fresh look at an aging disease. Ophthalmic Physiol Opt. 1999;19:210-222.

3. Weiss JS, Moller HU, Lisch W, et al. The IC3D classification of the corneal dystrophies. Cornea. 2008;27 Suppl 2:S1-S83.

4. Higa A, Sakai H, Sawaguchi S, et al. Prevalence of and risk factors for cornea guttata in a population-based study in a southwestern island of Japan: the Kumejima study. Arch.Ophthalmol. 2011;129:332-336.

5. Zoega GM, Fujisawa A, Sasaki H, et al. Prevalence and risk factors for cornea guttata in the Reykjavik Eye Study. Ophthalmology. 2006;113:565-569.

6. Fuchs EE. Dystrophia epithelialis corneae. Albrecht Von Graefes Arch Klin Exp Ophthalmol. 1910;76:478-508.

7. Slettedal JK, Lyberg T, Roger M, Beraki K, Ramstad H, Nicolaissen B. Regeneration with proliferation of the endothelium of cultured human donor corneas with extended postmortem time. Cornea. 2008;27:212-219.

8. Gottsch JD, Sundin OH, Liu SH, et al. Inheritance of a novel COL8A2 mutation defines a distinct early-onset subtype of fuchs corneal dystrophy. Invest Ophthalmol Vis Sci. 2005;46:1934-1939.

9. Rosenblum P, Stark WJ, Maumenee IH, Hirst LW, Maumenee AE. Hereditary Fuchs’ Dystrophy. Am J Ophthalmol. 1980;90:455-462.

10. Vithana EN, Morgan P, Sundaresan P, et al. Mutations in sodiumborate cotransporter SLC4A11 cause recessive congenital hereditary endothelial dystrophy (CHED2). Nat Genet. 2006;38:755-757.

11. Abramowicz MJ, Buquerque-Silva J, Zanen A. Corneal dystrophy and perceptive deafness (Harboyan syndrome): CDPD1 maps to 20p13. J Med Genet. 2002;39:110-112.
12. Vithana EN, Morgan PE, Ramprasad V, et al. SLC4A11 mutations in Fuchs endothelial corneal dystrophy. Hum Mol Genet. 2008;17:656-666.

13. Bainbridge KE, Hoffman HJ, Cowie CC. Diabetes and hearing impairment in the United States: audiometric evidence from the National Health and Nutrition Examination Survey, 1999 to 2004. Ann Intern Med. 2008;149:1-10.

14. Ventry IM, Weinstein BE. Identification of elderly people with hearing problems. ASHA. 1983;25:37-42.

15. Weinstein BE. Validity of a screening protocol for identifying elderly people with hearing problems. ASHA. 1986;28:41-45.

16. Lichtenstein MJ, Bess FH, Logan SA. Validation of screening tools for identifying hearing-impaired elderly in primary care. JAMA. 1988;259:2875-2878.

17. Lichtenstein MJ, Bess FH, Logan SA. Diagnostic performance of the hearing handicap inventory for the elderly (screening version) against differing definitions of hearing loss. Ear Hear. 1988;9:208-211.

18. McBride WS, Mulrow CD, Aguilar C, Tuley MR. Methods for screening for hearing loss in older adults. Am J Med Sci. 1994;307:40-42.

19. Sindhusake D, Mitchell P, Smith W, et al. Validation of self-reported hearing loss. The Blue Mountains Hearing Study. Int J Epidemiol. 2001;30:1371-1378

20. Romero MF, Fulton CM, Boron WF. The SLC4 family of HCO 3 transporters. Pflugers Arch. 2004;447:495-509.

21. Desir J, Moya G, Reish O, et al. Borate transporter SLC4 A11 mutations cause both Harboyan syndrome and non-syndromic corneal endothelial dystrophy. J Med Genet. 2007;44:322-326.

22. Park M, Li Q, Shcheynikov N, Muallem S, Zeng W. Borate transport and cell growth and proliferation. Not only in plants. Cell Cycle. 2005;4:24-26.

23. Groger N, Frohlich H, Maier H, et al. SLC4A11 prevents osmotic imbalance leading to corneal endothelial dystrophy, deafness, and polyuria. $J$ Biol Chem. 2010;285:14467-14474.

24. Mulrow CD, Tuley MR, Aguilar C. Discriminating and responsiveness abilities of two hearing handicap scales. Ear Hear. 1990;11:176-180.
Clinical Ophthalmology

\section{Publish your work in this journal}

Clinical Ophthalmology is an international, peer-reviewed journal covering all subspecialties within ophthalmology. Key topics include: Optometry; Visual science; Pharmacology and drug therapy in eye diseases; Basic Sciences; Primary and Secondary eye care; Patient Safety and Quality of Care Improvements. This journal is indexed on

Submit your manuscript here: http://www.dovepress.com/clinical-ophthalmology-journal

\section{Dovepress}

PubMed Central and CAS, and is the official journal of The Society of Clinical Ophthalmology (SCO). The manuscript management system is completely online and includes a very quick and fair peer-review system, which is all easy to use. Visit http://www.dovepress.com/ testimonials.php to read real quotes from published authors. 